\title{
Reproductive success or failure in four breed groups of beef bulls
}

\section{Sílvio Renato Oliveira Menegassi ${ }^{1}$, Júlio Otávio Jardim Barcellos ${ }^{1}$, Vanessa Peripolli², Eduardo Antunes Dias ${ }^{1}$, João Batista Gonçalves Costa Junior ${ }^{3}$, Maitê de Moraes Vieira1, Fernanda Gomes Moojen ${ }^{1}$}

\footnotetext{
${ }^{1}$ Universidade Federal do Rio Grande do Sul, Departamento de Zootecnia, Porto Alegre, RS, Brasil.

${ }^{2}$ Universidade de Brasília, Campus Darcy Ribeiro, Departamento de Zootecnia, Brasília, DF, Brasil.

${ }^{3}$ Empresa Brasileira de Pesquisa Agropecuária, Embrapa Gado de Corte, Campo Grande, MS, Brasil.
}

\begin{abstract}
The objective of this study was to determine the main causes of failure in bull breeding using a soundness evaluation in Rio Grande do Sul State/Brazil. We evaluated 19,836 bulls from 15 different breeds with ages ranging from two to eight years. The failures of bulls in each step were analyzed by logistic regression. The binary logistic regression was applied because the response variable had only two responses: Success (1) and Failure (0). Older bulls are more likely to be rejected than are younger bulls, regardless of their genetic group. Depending on the step of the assessment, one or another group is rejected. All steps of bull breeding soundness evaluation (BBSE) are important, with special attention to the failures of the behavioral evaluation (libido and physical ability). A BBSE performed before the breeding season reduces the risk of sub-fertile bulls in the herd.
\end{abstract}

Key Words: BBSE, fertility, mounting ability, scrotal circumference

\section{Introduction}

More than $90 \%$ of cattle reproduction in Brazil is conducted by natural breeding. It is well-documented that bull selection affects the performance of the herd (Parkinson, 2004; Ellis et al., 2005); therefore the use of reliable methods to evaluate the reproductive potential, such as the bull breeding soundness evaluation (BBSE), is critical in ranch management.

The bull breeding soundness evaluation is seen as a quick, reliable and cost-effective method. A properly performed and interpreted evaluation provides a useful management tool to reduce the risk of sub-fertile bulls in the herd (McGowan et al., 2002). The yearly assessment of bull fertility potential remains a key management tool to achieve higher reproductive performance. The use of BBSE increased births by $31 \%$ (13.8 calves/bull/year) and increased production by $24 \mathrm{~kg}$ of calf/cow/year, leading to an income of US $\$ 19.37$ for each dollar invested (Menegassi et al., 2011a). Therefore, reproductive success will continue to depend mainly on the capacity to evaluate all available information coming from BBSE (Foote, 2003).

Received October 22, 2014 and accepted May 5, 2015.

Corresponding author: femoojen@hotmail.com

http://dx.doi.org/10.1590/S1806-92902015000700002

Copyright $\odot 2015$ Sociedade Brasileira de Zootecnia. This is an Open Access article distributed under the terms of the Creative Commons Attribution Non-Commercial License, which permits unrestricted non-commercial use, distribution, and reproduction in any medium, provided the original work is properly cited.
The bull breeding soundness evaluation consists of a general clinical evaluation, an internal and external genital system evaluation, a scrotal circumference measurement, the evaluation of physical and morphological aspects of the semen, and an assessment of sexual behavior (Barth, 2000). The test of sexual behavior is easy to perform and an important BBSE step (Rossi et al., 2009). On the other hand, dental conditions and structural lesions have been the main causes of culling in adult bulls, while testicular hypoplasia is the main cause of culling in young bulls (Acuña and Campero, 1997).

It is also important to examine libido and social behavior before breeding (Menegassi et al., 2011b), even though this step is not usually included in the BBSE. There is strong evidence that demonstrates that bulls should be tested for serving ability before the beginning of the breeding season to avoid the selection of unfit bulls (Hoflack et al., 2006). The objective of this study was to determine the causes of failure in four breed groups of bulls through the use of the BBSE, as well as to evaluate the importance of the behavioral assessment as a mandatory step.

\section{Material and Methods}

Data from reproductive exams of 19,836 bulls in Rio Grande do Sul State, Brazil, were acquired from the Program for Reproductive Evaluation of Bulls (PARTO), which carried out the reproductive evaluation of bulls on beef cattle farms in Rio Grande do Sul State prior to the 
breeding season (September and October) over the course of four years, starting in 2000 .

All of the bulls were kept in the same feeding conditions: before seven months of age, they were fed breast milk; they were weaned at seven months, and then were grazed on ryegrass (Lolium multiflorum) until 12 months; between 12 and 18 months all animals were raised under field conditions with natural pasture, and between 18 and 24 months they were again grazed on ryegrass pastures. Throughout the examination period, the animals received mineral supplementation and water ad libitum.

Four breed groups were used: 10,407 British bulls (Aberdeen Angus, Red Angus, Hereford, Polled Hereford, Shorthorn, and Devon), 6,827 Synthetic bulls (Brangus, Braford, Santa Gertrudis, and Montana), 1,445 Continental bulls (Charolais and Limousin), and 1,157 Zebu bulls (Nellore, Brahman, and Tabapuã), with ages ranging from two to eight years.

Reproductive evaluations were conducted in 54 cities in Rio Grande do Sul State by trained veterinarians. The exam evaluation consisted of four steps:

Step I - General clinical evaluation: eyes, teeth, body condition score, and locomotion system (hooves, legs, articulations, back);

Step II - Special clinical evaluation; foreskin, penis, scrotum, testicles, epididymis, scrotal circumference (SC), seminal vesicles, and vas deferens ampullae. The scrotal circumference was determined by pulling the testicles to the bottom of the scrotum and taking the measurement around the largest circumference using a metal tape, with an immediate repetition. The scrotal circumference (SC) should reach at least $32 \mathrm{~cm}$ in all groups (Menegassi et al., 2011c) to pass;

Step III - Semen evaluation: volume, motility, vigor, turbulence, and concentration. Semen was collected mostly using electro-ejaculation or by massaging the seminal vesicles and ampullae of the vas deferens or, in some cases, using an artificial vagina. Mass motion (MM) was determined by placing a drop of semen on a pre-warmed microscope slide and examining the edge of the drop using a 40x magnification. Mass motion received a score ranging from zero to five crosses, as follows: $0=$ no swirl, $+=$ no swirl with generalized oscillation of individual sperm only, $++=$ very slow distinct swirl, $+++=$ slow distinct swirl, $++++=$ moderately fast distinct swirl and eddies, and +++++ $=$ fast distinct swirls and eddies with appearance of good quality semen. Spermatozoon motility was examined under a bright-field microscope (LEICA CME, Buffalo, New York, USA) at a magnification of $100 \mathrm{x}$ with a $5 \mu \mathrm{L}$ aliquot of semen placed on a warmed $\left(37^{\circ} \mathrm{C}\right)$ slide and covered with a coverslip. Sperm motility (M) was evaluated as a percentage of sperm movement (0 to 100\%). Vigor (VIG) was evaluated using a scale of 0 to 5 , based on the sperm progressive movement, in which $0=$ none, $1=$ very weak, 2 = weak, 3 = intermediate, $4=$ strong, and $5=$ very strong;

Step IV - Behavior: test of libido and physical ability to perform copulation. Libido was considered as the intention, desire, or urges to mount a cow, and physical ability was defined as the achievement of complete sexual intercourse. Libido and physical ability tests were conducted in a pen with two cows that were not necessarily in estrus. Initially, the bulls were kept together in a side pen to watch other bulls mounting for 10 to $15 \mathrm{~min}$ and thus be pre-stimulated to perform the tests. The bulls were placed in pairs for the test, and the pairs were kept together for a maximum time of $10 \mathrm{~min}$. When a bull became very uneasy, very apathetic, or too aggressive, it was tested with a cow in estrus in a pen or field, so all animals had a second chance to display sexual behavior.

The sequence of BBSE was general clinical evaluation, special evaluation, semen, and behavior (libido and physical ability). When a bull did not pass one of the steps, it did not perform the subsequent step.

For the analysis of variance, the animals received a score in each step. Scores closer to one represented a greater passing rate more than those far from one. Data were analyzed using the SAS software (Statistical Analysis System, version 9.3). To investigate the rate of success in each stage of the reproductive evaluation, an analysis of variance (PROC GLIMMIX; SAS, version 9.3) was used to compare the different ages $(2,3,4,5,6,7$, and 8$)$ and four breed groups (British, Synthetic, Continental, and Zebu). The means were compared by using Tukey's test at $5 \%$. The failures of bulls in each step were analyzed by logistic regression (PROC LOGISTIC; SAS, version 9.3). The binary logistic regression was applied because the response variable had only two responses: Success (1) and Failure (0). Each step of the andrological evaluation was regarded as a dependent variable (response variable), while ages and breed groups were considered independent variables (explanatory variables). The coefficients (odds ratio, OR) of each independent variable were observed in order to estimate the success or failure level in each step of the andrological evaluation.

The values of the estimate column in Tables 1-4 define the probability of how the event occurred. Values lower than one mean OR to failures and values greater than one mean OR to success. If the value was lower than 1 , it means that the variable on the left side that was confronted with the right side showed a negative 
probability of occurrence for the evaluated event - in this case, the probability of failure. In this case, to find the probability value of this negative event, it is necessary to find the ratio 1/estimate from the observed estimate. On the other hand, if the value of the estimate was greater than 1 , then the value observed in the estimate was its own and was related to success. The $95 \%$ confidence intervals were used to determine the significance level of each variable. The estimate odds ratios were significant if the confidence limits did not exceed 1.

A multiple correspondence analysis (PROC CORRESP; SAS, version 9.3) was performed to identify the relationship of the components of each step of the andrological evaluation for age and breed groups.

\section{Results}

For the general clinical evaluation, the British group showed a 3.15 times higher probability of success than the Continental group; however, the British group showed a 2.09 times $(1 / 0.478=2.09)$ higher probability of failure than the Synthetic group. The Continental group showed a $6.62(1 / 0.151=6.62)$ and $3.36(1 / 0.298=3.3557)$ times higher probability of failure than the Synthetic and Zebu

Table 1 - Odds ratio estimates and 95\% confidence limits to success or failure in the general clinical evaluation

\begin{tabular}{|c|c|c|c|}
\hline \multirow{2}{*}{$\frac{\text { Label }}{\text { Brit vs Cont }}$} & \multirow{2}{*}{$\frac{\text { Estimate }}{3.15^{1}}$} & \multicolumn{2}{|c|}{$95 \%$ confidence limit } \\
\hline & & 1.366 & 7.279 \\
\hline Brit vs Synt & $0.48^{1}$ & 0.347 & 0.657 \\
\hline Brit vs Zebu & 0.94 & 0.609 & 1.449 \\
\hline Cont vs Synt & $0.15^{1}$ & 0.063 & 0.362 \\
\hline Cont vs Zebu & $0.30^{1}$ & 0.119 & 0.748 \\
\hline Synt vs Zebu & $1.97^{1}$ & 1.197 & 3.233 \\
\hline Age 2 vs 3 & 0.95 & 0.614 & 1.480 \\
\hline Age 2 vs 4 & 0.98 & 0.587 & 1.631 \\
\hline Age 2 vs 5 & 1.51 & 0.934 & 2.429 \\
\hline Age 2 vs 6 & $1.73^{1}$ & 1.108 & 2.699 \\
\hline Age 2 vs 7 & $3.68^{1}$ & 2.012 & 6.721 \\
\hline Age 2 vs 8 & $28.22^{1}$ & 20.441 & 38.968 \\
\hline Age 3 vs 4 & 1.03 & 0.568 & 1.855 \\
\hline Age 3 vs 5 & 1.58 & 0.900 & 2.774 \\
\hline Age 3 vs 6 & $1.82^{1}$ & 1.062 & 3.099 \\
\hline Age 3 vs 7 & $3.86^{1}$ & 1.969 & 7.559 \\
\hline Age 3 vs 8 & $29.61^{1}$ & 19.087 & 45.934 \\
\hline Age 4 vs 5 & 1.54 & 0.828 & 2.861 \\
\hline Age 4 vs 6 & 1.77 & 0.974 & 3.207 \\
\hline Age 4 vs 7 & $3.76^{1}$ & 1.828 & 7.729 \\
\hline Age 4 vs 8 & $28.85^{1}$ & 17.302 & 48.099 \\
\hline Age 5 vs 6 & 1.15 & 0.653 & 2.021 \\
\hline Age 5 vs 7 & $2.44^{1}$ & 1.216 & 4.904 \\
\hline Age 5 vs 8 & $18.74^{1}$ & 11.646 & 30.155 \\
\hline Age 6 vs 7 & $2.13^{1}$ & 1.084 & 4.171 \\
\hline Age 6 vs 8 & $16.32^{1}$ & 10.493 & 25.377 \\
\hline Age 7 vs 8 & $7.68^{1}$ & 4.208 & 14.000 \\
\hline
\end{tabular}

Brit - British; Cont - Continental; Synt - synthetic.

${ }^{1}$ Values lower than one mean estimates to failure, and values greater than one mean estimates to success. groups, respectively. The Synthetic group showed a 1.97 times higher probability of success than the Zebu group (Table 1).

The age of two years showed a $1.73,3.68$, and 28.22 times higher probability of success than ages 6,7 , and 8 , respectively. The age of three years showed a $1.82,3.86$, and 29.61 times higher probability of success than ages 6,7 , and 8 , respectively. The age of four years showed a 3.76 and 28.85 times higher probability of success than ages seven and eight, respectively. The age of five showed a 2.44 and 18.74 times higher probability of success than ages seven and eight, respectively. Age six years showed a 2.13 and 16.32 times higher probability of success than ages seven and eight. Age seven years showed a 7.68 times higher probability of success than age eight (Table 1).

Through the correspondence analysis, it was possible to notice a strong relationship between advanced ages and harms in the locomotion system (hooves, legs, articulations, back) in the general clinical evaluation for the Continental group (Figure 1).

For the special clinical evaluation, the British and Synthetic groups showed, respectively, a 2.23 and 2.14 times higher probability of success than the Zebu group (Table 2).

Table 2 - Odds ratio estimates and 95\% confidence limits to success or failure in the special clinical evaluation

\begin{tabular}{|c|c|c|c|}
\hline \multirow{2}{*}{$\frac{\text { Label }}{\text { Brit vs Cont }}$} & \multirow{2}{*}{$\frac{\text { Estimate }}{2.06}$} & \multicolumn{2}{|c|}{$95 \%$ confidence limit } \\
\hline & & 0.968 & 4.389 \\
\hline Brit vs Synt & 1.04 & 0.841 & 1.283 \\
\hline Brit vs Zebu & $2.23^{1}$ & 1.668 & 2.968 \\
\hline Cont vs Synt & 0.50 & 0.235 & 1.082 \\
\hline Cont vs Zebu & 1.08 & 0.490 & 2.379 \\
\hline Synt vs Zebu & $2.14^{1}$ & 1.569 & 2.926 \\
\hline Age 2 vs 3 & 1.12 & 0.860 & 1.464 \\
\hline Age 2 vs 4 & 0.89 & 0.635 & 1.258 \\
\hline Age 2 vs 5 & 1.17 & 0.831 & 1.646 \\
\hline Age 2 vs 6 & $1.85^{1}$ & 1.390 & 2.459 \\
\hline Age 2 vs 7 & $1.82^{1}$ & 1.075 & 3.068 \\
\hline Age 2 vs 8 & $1.96^{1}$ & 1.294 & 2.953 \\
\hline Age 3 vs 4 & 0.80 & 0.544 & 1.167 \\
\hline Age 3 vs 5 & 1.04 & 0.712 & 1.527 \\
\hline Age 3 vs 6 & $1.65^{1}$ & 1.183 & 2.297 \\
\hline Age 3 vs 7 & 1.62 & 0.933 & 2.809 \\
\hline Age 3 vs 8 & $1.74^{1}$ & 1.115 & 2.722 \\
\hline Age 4 vs 5 & 1.31 & 0.845 & 2.027 \\
\hline Age 4 vs 6 & $2.07^{1}$ & 1.394 & 3.072 \\
\hline Age 4 vs 7 & $2.03^{1}$ & 1.126 & 3.670 \\
\hline Age 4 vs 8 & $2.19^{1}$ & 1.334 & 3.589 \\
\hline Age 5 vs 6 & $1.58^{1}$ & 1.066 & 2.345 \\
\hline Age 5 vs 7 & 1.55 & 0.960 & 2.804 \\
\hline Age 5 vs 8 & $1.67^{1}$ & 1.020 & 2.740 \\
\hline Age 6 vs 7 & 0.98 & 0.562 & 1.718 \\
\hline Age 6 vs 8 & 1.06 & 0.670 & 1.670 \\
\hline Age 7 vs 8 & 1.08 & 0.571 & 2.028 \\
\hline
\end{tabular}

Brit - British; Cont - Continental; Synt - synthetic.

${ }^{1}$ Values lower than one mean estimates to failure, and values greater than one mean estimates to success. 
The age of two years showed a $1.85,1.82$, and 1.96 times higher probability of success than ages 6,7 , and 8 years, respectively. The age of three years showed a 1.65 and 1.74 times higher probability of success than ages six and eight years, respectively. The age of four years showed a 2.07, 2.03, and 2.19 times higher probability of success than ages 6,7 , and 8 , respectively. The age of five years showed a 1.58 and 1.67 times higher probability of success than ages six and eight years, respectively (Table 2).

It is noteworthy that the scrotal circumference in the eight-year-old group was inconsistent with this age (Figure 2).

For the semen evaluation, the British, Continental, and Synthetic groups showed, respectively, a $9.52(1 / 0.105=$ 9.52), $17.85(1 / 0.056=17.85)$, and $9.52(1 / 0.105=9.52)$ times higher probability of failure than the Zebu group (Table 3). In the semen evaluation, both the Synthetic and Continental groups had higher failure rates due, probably, to the poor results in the semen analyses (mass motion, motility, and vigor), as shown in the correspondence analysis (Figure 3).

For the behavioral evaluation, the age of two years showed a 1.72 times $(1 / 0.583=1.72)$ higher probability of failure than the age of three years (Table 4).

In the behavioral evaluation, there was more dispersion in the results of the breed group and age group variables as demonstrated in the correspondence analysis. Concerning libido, the three-year-old Synthetic bulls showed the highest failure rate, while four-year-old bulls from the Continental group had the highest rate of success for mounting capacity, but negative results for libido. The

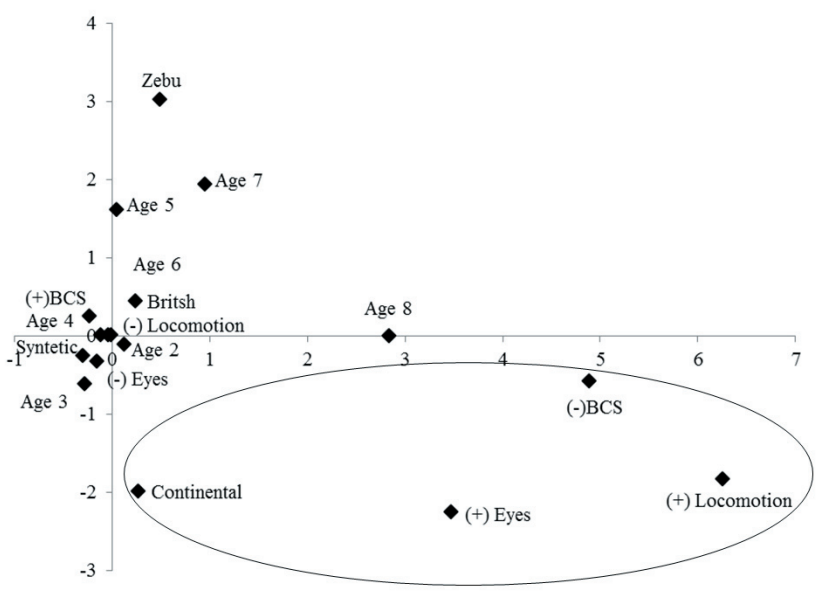

BCS - body condition score.

Figure 1 - Multiple correspondence analysis for the general clinical evaluation. five-year-old British bulls, in turn, demonstrated to be associated with a rate of success for libido but negatively with mounting capacity (Figure 4). In the general clinical evaluation, the Tukey test did not show any difference in the British group between the 2-, 3-, 4-, and 5-year-old animals. However, there was some difference $(\mathrm{P}<0.05)$

Table 3 - Odds ratio estimates and 95\% confidence limits to success or failure in the semen evaluation

\begin{tabular}{|c|c|c|c|}
\hline \multirow{2}{*}{$\begin{array}{l}\text { Label } \\
\text { Brit vs Cont }\end{array}$} & \multirow{2}{*}{$\begin{array}{c}\text { Estimate } \\
1.87\end{array}$} & \multicolumn{2}{|c|}{$95 \%$ confidence limit } \\
\hline & & 0.444 & 7.842 \\
\hline Brit vs Synt & 1.00 & 0.683 & 1.470 \\
\hline Brit vs Zebu & $0.11^{1}$ & 0.015 & 0.759 \\
\hline Cont vs Synt & 0.54 & 0.126 & 2.292 \\
\hline Cont vs Zebu & $0.06^{1}$ & 0.005 & 0.636 \\
\hline Synt vs Zebu & $0.11^{1}$ & 0.014 & 0.767 \\
\hline Age 2 vs 3 & 1.18 & 0.710 & 1.958 \\
\hline Age 2 vs 4 & 1.06 & 0.570 & 1.964 \\
\hline Age 2 vs 5 & 1.65 & 0.917 & 2.973 \\
\hline Age 2 vs 6 & 1.73 & 0.975 & 3.072 \\
\hline Age 2 vs 7 & 0.97 & 0.232 & 4.048 \\
\hline Age 2 vs 8 & 2.04 & 0.910 & 4.575 \\
\hline Age 3 vs 4 & 0.90 & 0.448 & 1.797 \\
\hline Age 3 vs 5 & 1.40 & 0.719 & 2.729 \\
\hline Age 3 vs 6 & 1.47 & 0.763 & 2.825 \\
\hline Age 3 vs 7 & 0.82 & 0.190 & 3.554 \\
\hline Age 3 vs 8 & 1.73 & 0.728 & 4.118 \\
\hline Age 4 vs 5 & 1.56 & 0.735 & 3.315 \\
\hline Age 4 vs 6 & 1.64 & 0.778 & 3.439 \\
\hline Age 4 vs 7 & 0.92 & 0.204 & 4.125 \\
\hline Age 4 vs 8 & 1.93 & 0.757 & 4.913 \\
\hline Age 5 vs 6 & 1.05 & 0.512 & 2.146 \\
\hline Age 5 vs 7 & 0.59 & 0.132 & 2.612 \\
\hline Age 5 vs 8 & 1.24 & 0.495 & 3.085 \\
\hline Age 6 vs 7 & 0.56 & 0.127 & 2.478 \\
\hline Age 6 vs 8 & 1.18 & 0.477 & 2.916 \\
\hline Age 7 vs 8 & 2.10 & 0.429 & 10.332 \\
\hline
\end{tabular}

Brit - British; Cont - Continental; Synt - synthetic.

${ }^{1}$ Values lower than one mean estimates to failure, and values greater than one mean estimates to success.

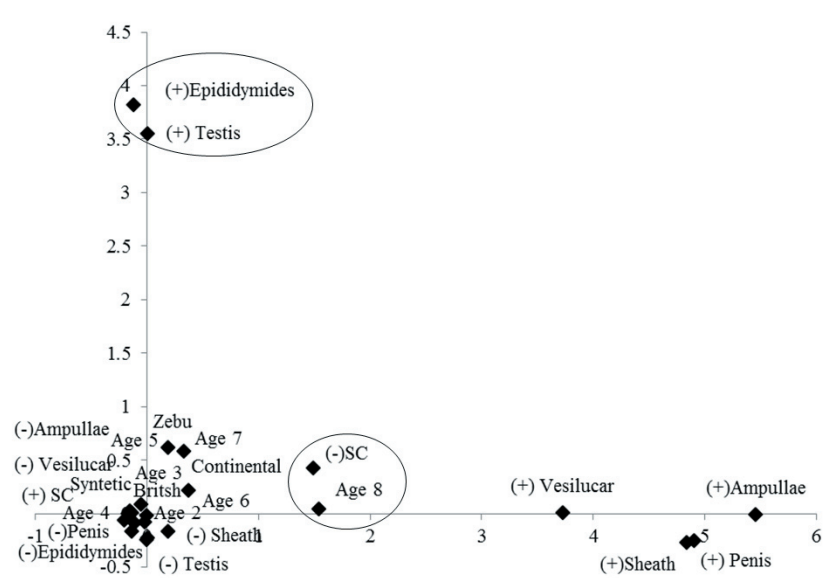

SC - scrotal circumference.

Figure 2 - Multiple correspondence analysis for the special clinical evaluation. 
between these animals and the 6-, 7-, and 8-year-old bulls, as well as among the older groups. No difference $(\mathrm{P}>0.05)$ was found between ages in the Continental group. In the Synthetic group, the rate of success did not vary $(\mathrm{P}>0.05)$

Table 4 - Odds ratio estimates and $95 \%$ confidence limits to success or failure in the behavioral evaluation

\begin{tabular}{|c|c|c|c|}
\hline \multirow{2}{*}{$\frac{\text { Label }}{\text { Brit vs Cont }}$} & \multirow{2}{*}{$\frac{\text { Estimate }}{0.96}$} & \multicolumn{2}{|c|}{$95 \%$ confidence limit } \\
\hline & & 0.292 & 3.127 \\
\hline Brit vs Synt & 1.04 & 0.762 & 1.408 \\
\hline Brit vs Zebu & 0.67 & 0.332 & 1.332 \\
\hline Cont vs Synt & 1.08 & 0.327 & 3.597 \\
\hline Cont vs Zebu & 0.70 & 0.180 & 2.694 \\
\hline Synt vs Zebu & 0.64 & 0.313 & 1.319 \\
\hline Age 2 vs 3 & $0.58^{1}$ & 0.370 & 0.920 \\
\hline Age 2 vs 4 & 0.70 & 0.444 & 1.091 \\
\hline Age 2 vs 5 & 0.97 & 0.623 & 1.522 \\
\hline Age 2 vs 6 & 0.63 & 0.370 & 1.062 \\
\hline Age 2 vs 7 & 1.34 & 0.629 & 2.867 \\
\hline Age 2 vs 8 & 1.03 & 0.506 & 2.087 \\
\hline Age 3 vs 4 & 1.19 & 0.671 & 2.118 \\
\hline Age 3 vs 5 & 1.67 & 0.942 & 2.959 \\
\hline Age 3 vs 6 & 1.08 & 0.569 & 2.030 \\
\hline Age 3 vs 7 & 2.30 & 0.997 & 5.316 \\
\hline Age 3 vs 8 & 1.76 & 0.798 & 3.895 \\
\hline Age 4 vs 5 & 1.40 & 0.794 & 2.467 \\
\hline Age 4 vs 6 & 0.90 & 0.479 & 1.696 \\
\hline Age 4 vs 7 & 1.93 & 0.839 & 4.442 \\
\hline Age 4 vs 8 & 1.48 & 0.671 & 3.255 \\
\hline Age 5 vs 6 & 0.64 & 0.343 & 1.209 \\
\hline Age 5 vs 7 & 1.38 & 0.600 & 3.170 \\
\hline Age 5 vs 8 & 1.06 & 0.480 & 2.322 \\
\hline Age 6 vs 7 & 2.14 & 0.891 & 5.153 \\
\hline Age 6 vs 8 & 1.64 & 0.711 & 3.783 \\
\hline Age 7 vs 8 & 0.77 & 0.282 & 2.074 \\
\hline
\end{tabular}

Brit - British; Cont - Continental; Synt - synthetic.

${ }^{1}$ Values lower than one mean estimates to failure, and values greater than one mean estimates to success.

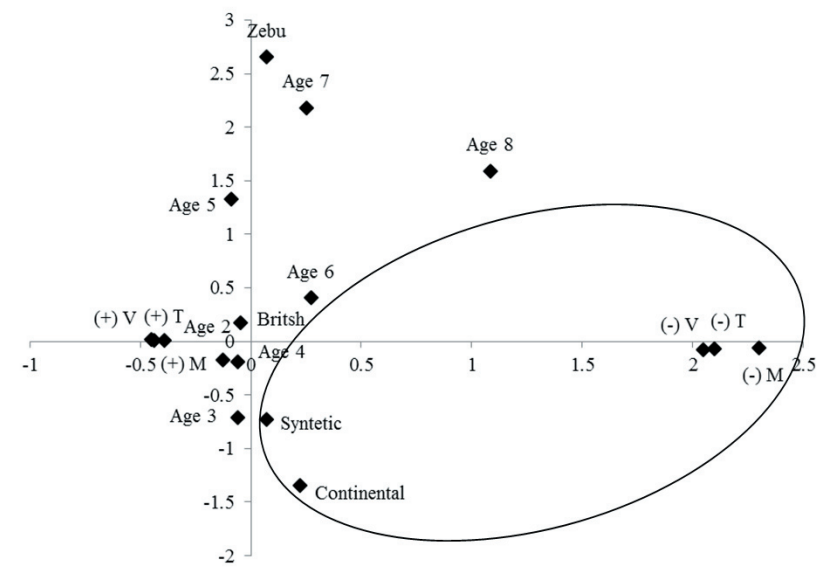

V - vigor; T - turbulence; $\mathrm{M}$ - motility.

Figure 3 - Multiple correspondence analysis for the semen clinical evaluation. for the 2-6-year-old bulls, but a difference $(\mathrm{P}<0.05)$ was detected between this age group and the 7-8-year-old bulls, as well as between the seven- and eight-year-old bulls. In the Zebu group, the rate of success did not vary $(\mathrm{P}>0.05)$ for the 2-7-year-old bulls, but a difference was detected $(\mathrm{P}<0.05)$ between this age group and the eightyear-old bulls (Table 5). However, the different breed groups and ages did not cause differences $(\mathrm{P}>0.05)$ in the rates of success concerning the special clinical evaluation (Table 5).

In the special clinical evaluation, semen evaluation, and behavioral assessment, the Tukey test did not show differences $(\mathrm{P}>0.05)$ in rates of success between the Continental, Synthetic, and Zebu groups in terms of the evaluated ages. However, in the British group, differences were more evident between two-year-old and 7-8-year-old bulls (Table 5).

The rate of success in the semen evaluation showed no differences $(\mathrm{P}>0.05)$ for the analyzed groups and ages, with the exception of the eight-year-old British group against the two-year-olds. This suggests that, over the years, those animals may have increased their chances of having testicular pathologies (Table 5).

For the behavioral assessment, the analyses showed that for the British breed, the younger groups $(2,3,4$, and 5 years old) and the seven-year-olds showed no significant differences $(\mathrm{P}>0.05)$ when compared with animals aged six and eight years; however, the age of seven years showed a lower rate of success $(\mathrm{P}<0.05)$ than the younger groups.

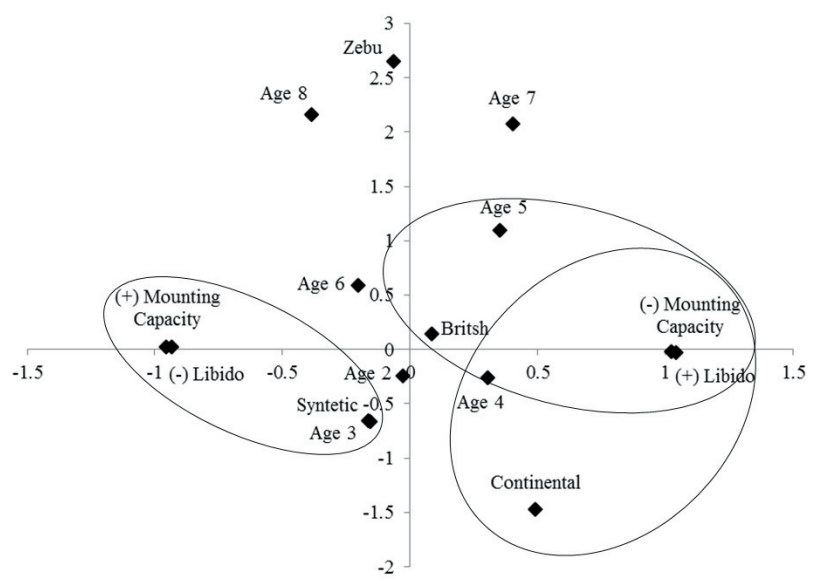

Figure 4 - Multiple correspondence analysis for the behavioral clinical evaluation. 
Table 5 - Indices of success at each stage of the reproductive evaluation for each breed group and age

\begin{tabular}{|c|c|c|c|c|c|c|c|c|c|}
\hline \multirow[b]{2}{*}{ Breed group } & \multicolumn{7}{|c|}{ Approvals by age } & \multirow[b]{2}{*}{ Mean } & \multirow[b]{2}{*}{ SD } \\
\hline & 2 & 3 & 4 & 5 & 6 & 7 & 8 & & \\
\hline \multicolumn{10}{|c|}{ General clinical evaluation } \\
\hline Continental & $0.91 \mathrm{~B}$ & 1.00 & 1.00 & 1.00 & $1.00 \mathrm{AB}$ & 1.00 & 0.66 & 0.94 & 0.025 \\
\hline Synthetic & $0.99 \mathrm{aA}$ & $0.99 \mathrm{a}$ & $0.99 \mathrm{a}$ & $0.98 \mathrm{a}$ & $0.98 \mathrm{aA}$ & $0.91 b$ & $0.62 \mathrm{c}$ & 0.92 & 0.003 \\
\hline Zebu & $0.98 \mathrm{aA}$ & $1.00 \mathrm{a}$ & $0.97 \mathrm{a}$ & $0.98 \mathrm{a}$ & $0.94 \mathrm{aAB}$ & $0.92 \mathrm{a}$ & $0.66 \mathrm{~b}$ & 0.92 & 0.006 \\
\hline \multicolumn{10}{|c|}{ Special clinical evaluation } \\
\hline Synthetic & 0.92 & 0.93 & 0.92 & 0.93 & 0.91 & 0.93 & 0.92 & 0.92 & 0.005 \\
\hline Zebu & 0.87 & 0.94 & 0.92 & 0.94 & 0.86 & 0.89 & 0.91 & 0.90 & 0.009 \\
\hline \multicolumn{10}{|c|}{ Semen evaluation } \\
\hline British & $0.97 \mathrm{a}$ & $0.97 \mathrm{aA}$ & $0.96 \mathrm{a}$ & $0.97 \mathrm{aA}$ & $0.95 \mathrm{ab}$ & $0.93 \mathrm{ab}$ & $0.92 b$ & 0.95 & 0.003 \\
\hline Continental & 0.95 & $0.97 \mathrm{AB}$ & 0.86 & $1.00 \mathrm{~A}$ & 1.00 & 1.00 & 1.00 & 0.97 & 0.031 \\
\hline Synthetic & 0.95 & $0.94 \mathrm{~B}$ & 0.95 & $0.93 \mathrm{AB}$ & 0.95 & 0.90 & 0.95 & 0.94 & 0.005 \\
\hline Synthetic & 0.95 & 0.98 & 0.96 & 0.94 & 0.95 & 0.90 & 0.94 & 0.94 & 0.006 \\
\hline Zebu & $0.99 \mathrm{a}$ & $0.99 a$ & $0.95 \mathrm{a}$ & $0.87 \mathrm{~b}$ & $0.98 \mathrm{a}$ & $0.92 \mathrm{a}$ & $0.94 \mathrm{a}$ & 0.95 & 0.011 \\
\hline
\end{tabular}

SD - standard deviation.

a,B - Means followed by different letters in the same rows or columns are significantly different $(\mathrm{P}<0.05)$.

\section{Discussion}

The failure rates of the breed groups increased with age, as reported by other researchers, even when they considered breeds rather than genetic groups (Blockey, 1984; Acuña and Campero, 1997; Gottschall and Mattos, 1997; Cumming, 2003; Menegassi et al., 2012).

In Argentina, 8,739 young bulls (18 to 24 months old) and 14,255 adult bulls (from 36 months old) of the Aberdeen Angus, Hereford, Polled Hereford, Limousin, and Jersey breeds were examined, and higher percentages of failure were found in adults as compared with young animals (12.6\% and $3.8 \%$, respectively) (Acuña and Campero, 1997). The general clinical evaluation contributed to most failures in adult bulls. We found that the Continental group was more likely to be rejected than were all of the other groups because of its heavy body size.

The physical causes of failure are consistent with other findings (McGowan et al., 2002; Cumming, 2003), suggesting that bulls develop problems along their service in the field (Ellis et al., 2005), especially in large natural pasture areas with irregular topography, which requires more physical activity during the breeding season. The mounting activity over the years leads to a natural wear of the bull's physical ability, mainly affecting the locomotor system. This makes the bull unable to reproduce.

Bulls of the Zebu, British, and Continental groups with low SC $(<32 \mathrm{~cm})$, as the result of genetic and nutritional causes, failed at all tested ages, irrespective of the presence of testicular hypoplasia. In Argentina, testicular hypoplasia was the main pathology found in young bulls (Acuña and Campero, 1997). Inadequate SC was the main cause of failure in 16- and 19-month-old bulls (Kennedy et al., 2002) using the Guidelines of the American Society for Theriogenology. This pathology includes small testes, low sperm concentration, low motility, low percentage of live sperm, and protoplasmic droplets involving significant histological changes (Galloway, 1989).

Young bulls reached puberty with a SC of $30.5 \mathrm{~cm}$ $( \pm 1.5 \mathrm{~cm})$ at 17.9 months $( \pm 2.2$ months) (Siddiqui et al., 2008), similar to the failure level adopted for SC in this study. A recent trial (Menegassi et al., 2011c) reported that the average failure rates for bulls of four breed groups at two and three years of age were $13.78 \%$ and $13.42 \%$, respectively.

Thirty-one percent of five-year-old bulls and $49 \%$ of bulls over seven years old failed the andrological evaluation out of a total of 1,100 bulls examined (Cumming, 2003). The main causes of failure were problems in the locomotor system, penis, testicles, and libido. Such findings corroborate our results, which have demonstrated an increase in failures with age.

In contrast, there are reports of a failure rate of $24.77 \%$ in 2,474 Nellore bulls at ages ranging from two to six years (Fonseca et al., 1997). Semen quality problems also represented the main cause of failure in 11.6\% (Gottschall and Mattos, 1997) and 13.7\% (Kennedy et al., 2002) of the evaluated bulls, showing that $13.6 \%$ of 16 - and 19 -month- 
old animals failed the semen exam, and $10.2 \%$ of them did not pass the physical evaluation.

The reproductive evaluation of 335 bulls (Gottschall and Mattos, 1997) reported inability in $12.2 \%$, and more than $55 \%$ of such failures were caused by either low sperm motility or high sperm pathology. Similar to our findings, the causes of failure were more frequent in 8-to-10-yearold bulls, which represented $30.8 \%$ of the total eliminated by the andrological evaluation, mainly as the result of heat stress and reproductive diseases.

Although the behavioral assessment of bulls is not often carried out, failures in this step accounted for $42.5 \%$ of the total failure rate of $20.7 \%$ due to the absence of libido and mounting capacity in mature bulls (Blockey, 1984). However, considering the four steps of the andrological evaluation, a recent study found out that the results of the behavioral assessment did not differ from those obtained through either the general clinical evaluation or the seminal exam, with an average failure rate of $4.39 \%$ out of a total mean failure rate of $17.12 \%$ of bulls at all ages (Menegassi et al., 2011b).

The evaluation of 7,021 young and 5,669 adult bulls (Acuña and Campero, 1997) showed 5.18\% and 6.43\% of failures for libido and physical ability, respectively, stressing the importance of this step during the reproductive evaluation of bulls. Bulls with good semen quality have limited capacity to maximize calf production because of low mounting ability (Katz, 2008).

Several factors can affect the expression of libido in the field, such as breed, age, bull/cow ratio, previous reproductive experience, climate, and how the evaluation of these characteristics is carried out (Coulter and Kozub, 1989; Chenoweth, 1994; Petherick, 2005). In this study, the hierarchy was the main cause of failure in the behavior evaluation. Although libido evaluation and mating ability are not sufficient to predict reproductive success, it is prudent to use bulls that passed all stages of the BBSE, including libido and ability to mount (Parkinson, 2004).

The Zebu group showed the lowest level of association with physical failures, with the exception of the special clinical evaluation, when compared with the British group, because the Zebu breed is calmer and less anxious during mating (Costa e Silva et al., 1998).

\section{Conclusions}

Older bulls are more likely to be rejected than are younger bulls, regardless of their genetic group. Depending on the step of assessment, one or another group is rejected. All steps of bull breeding soundness evaluation are important, with special attention to the failures in the behavioral evaluation (libido and physical ability). Bull breeding soundness evaluation performed before the breeding season reduces the risk of sub-fertile bulls in the herd.

\section{Acknowledgments}

The authors thank Ministério da Ciência, Tecnologia e Inovação/Conselho Nacional de Desenvolvimento Científico e Tecnológico for the funding support (150909/2014-4).

\section{References}

Acuña, C. M. and Campero, C. M. 1997. Problemas reprodutivos, clínicos e a prova de capacidade de serviço em 22,994 touros de raças de carne na Argentina. p.6-8. In: 25th Jornadas Uruguaias de Buiatria e 9th Congresso Latino de Buiatria, Paysandu, Uruguay.

Barth, A. D. 2000. Bull breeding soundness evaluation manual. 2nd ed. The Western Canadian Association of Bovine Practitioners, Saskatoon, SK.

Blockey, M. A. B. 1984. Using bull fertility to increase herd fertility. p.509-527. In: Cattle production beef. Hungerford, T. G., ed. University of Sydney, Australia.

Chenoweth, P. J. 1994. Bull behavior, sex-drive and management. p.319-330. In: Factors affecting calf crop. Fields, M. J. and Sand, R. S., eds. CRC Press, Boca Raton, FL.

Costa e Silva, E. V.; Sereno, J. R. B.; Nogueira Júnior, N.; Nogueira, S. A. F. and Batistote, E. 1998. Redução da proporção touro:vaca no Estado de Mato Grosso do Sul, Brasil. p.102-104. In: Anais da 35a Reunião Anual da Sociedade Brasileira de Zootecnia. Sociedade Brasileira de Zootecnia, Botucatu.

Coulter, G. H. and Kozub, G. C. 1989. Efficacy of methods used to test fertility of beef bulls used for multiple-sire breeding under range conditions. Journal of Animal Science 67:1757-1766.

Cumming, B. 2003. Los toros con mala solidez estructural pueden llevar a su negocio ganadero a la quiebra. Revista Hereford 633:88-97.

Ellis, R. W.; Rupp, G. P.; Chenoweth, P. J.; Cundiff, L. V. and Lunstra, D. D. 2005. Fertility of yearling beef bulls during mating. Theriogenology 64:657-678. doi: 10.1016/j.theriogenology.2005.05.029

Fonseca, V. O.; Santos, N. R. and Malinski, P. R. 1997. Andrological Classification of zebu bulls based on scrotal perimeter and morpho-physic of the semen characteristics. Revista Brasileira de Reprodução Animal 21:36-39.

Foote, R. H. 2003. Fertility estimation: A review of past experience and future prospects. Animal Reproduction Science 75:119-139. doi: 10.1016/S0378-4320(02)00233-6

Galloway, D. B. 1989. Fatores que afetam a fertilidade do touro. Revista Brasileira de Reprodução Animal 2:27-46.

Gottschall, C. S. and Mattos, R. C. 1997. Achados de exames andrológicos em touros de corte Bos taurus e Bos indicus. Revista Brasileira de Reprodução Animal 21:25-28.

Hoflack, G.; Van Soom, A.; Maes, D.; de Kruif, A.; Opsomer, G. and Duchateau, L. 2006. Breeding soundness and libido examination in Belgium Blue and Holstein Friesian artificial insemination bulls in Belgium and the Netherlands. Theriogenology 66:207-216. doi: 10.1016/j.theriogenology.2005.11.003

Katz, L. S. 2008. Variation in male sexual behavior. Animal Reproduction Science 105:64-71. doi: 10.1016/j.anireprosci.2007.11.019

Kennedy, S. P.; Spitzer, J. C.; Hopkins, F. M.; Higdon, H. L. and Bridges, Jr. W. C. 2002. Breeding soundness evaluations of 3648 yearling beef bulls using the 1993 Society for Theriogenology guidelines. Theriogenology 58:947-961. 
McGowan, M. R.; Bertram, J. D.; Fordyce, G.; Fitzpatrick, L. A.; Miller, R. G.; Jayawarhana, G. A.; Doogan, V. J.; De Faveri, J. and Holroyd, R. G. 2002. Bull selection and use in northern Australia. I. Phisical traits. Animal Reproduction Science 71:25-37. doi: 10.1016/S0378-4320(02)00023-4

Menegassi, S. R. O.; Barcellos, J. O. J.; Lampert, V. N.; Borges, J. B. S. and Peripolli, V. 2011a. Bioeconomic impact of Bull breeding soundness examination in cow-calf systems. Revista Brasileira de Zootecnia 40:441-447. doi: 10.1590/S1516-35982011000200028

Menegassi, S. R. O.; Barcellos, J. O. J.; Peripolli, V. and Camargo, C. M. 2011b. Behavioral assessment during breeding soundness evaluation of beef bulls in Rio Grande do Sul. Animal Reproduction 8:77-80.

Menegassi, S. R. O.; Barcellos, J. O. J.; Peripolli, V.; Pereira, P. R. R. X.; Borges, J. B. S. and Lampert, V. N. 2011c. Measurement of scrotal circumference in beef bulls in Rio Grande do Sul. Arquivo Brasileiro de Medicina Veterinária e Zootecnia 63:87-93. doi: 10.1590/S0102-09352011000100014

Menegassi, S. R. O.; Barcellos, J. O. J.; Peripolli, V.; Borges, J. B. S. and Bernardi, M. L. 2012. Causes of rejection of beef bulls in breeding soundness evaluation. Revista Brasileira de Zootecnia 41:1648-1653.

Parkinson, T. J. 2004. Evaluation of fertility and infertility in natural service bulls. The Veterinary Journal 168:215-229. doi: 10.1016/ j.tvj1.2003.10.017

Petherick, J. C. 2005. A Review of some factors affecting the expression of libido in beef cattle and individual bull and herd fertility. Applied Animal Behaviour Science 90:185-205. doi: 10.1016/j.applanim.2004.08.021

Rossi, R. O. D. S.; Barreto Filho, J. B.; Carvalho, P. H. A.; Lopes, E. and Gonçalvez, T. M. 2009. Características andrológicas e do sêmen de touros do composto Red Norte (Nelore x Tabapuã x Red Angus x Sinepol). Arquivo Brasileiro de Medicina Veterinária e Zootecnia 61:1297-1301. doi: 10.1590/S0102-09352009000600007

Siddiqui, M. A. R.; Bhattacharjee, J.; Das, Z. C.; Islam, M. M.; Haque, M. A.; Parrish, J. J. and Shamsuddin, M. 2008. Crossbred bull selection for bigger scrotal and shorter age at puberty with potentials for better quality semen. Reproduction in Domestic Animal 43:74-79. doi: 10.1111/j.1439-0531.2007.00857 